\title{
Voltammetric pH measurements in unadulterated foodstuffs, urine, and serum with 3D-printed graphene/poly(lactic acid) electrodes
}

\author{
Fakher M. Rabboh and Glen D. O’Neil* \\ Department of Chemistry and Biochemistry, Montclair State University, Montclair, NJ 07043, \\ United States
}

*To whom correspondence should be addressed: oneilg@montclair.edu; (973) 655-3791

\begin{abstract}
The $\mathrm{pH}$ of a system is a critical descriptor of its chemistry - impacting reaction rates, solubility, chemical speciation, and homeostasis. As a result, $\mathrm{pH}$ is one of the most commonly measured parameters in food safety, clinical, and environmental laboratories. Glass $\mathrm{pH}$ probes are the gold standard for $\mathrm{pH}$ measurements, but suffer drawbacks including frequent recalibration, wet storage of the glass membrane, difficulty in miniaturization, and interferences from alkali metals. In this work, we describe a voltammetric $\mathrm{pH}$ sensor that uses a 3D-printed graphene/poly(lactic acid) filament electrode that is pretreated to introduce quinone functional groups to the graphene surface. After thoroughly characterizing the pretreatment parameters using outer-sphere and inner-sphere redox couples, we measured $\mathrm{pH}$ by reducing the surface-bound quinones, which undergo a $\mathrm{pH}$-dependent $2 \mathrm{e}-12 \mathrm{H}+$ reduction. The position of the redox peak was found to shift $60 \pm 2 \mathrm{mV} \mathrm{pH}-1$ at $25^{\circ} \mathrm{C}$, which is in excellent agreement with the theoretical value predicted by the Nernst Equation ( $-59.2 \mathrm{mV} \mathrm{pH}-1)$. Importantly, the sensors did not require the removal of dissolved oxygen prior to successful $\mathrm{pH}$ measurements. We investigated the impact of common interfering species $\left(\mathrm{Pb}_{2+}\right.$ and $\left.\mathrm{Cu}_{2+}\right)$ and found that there was no impact on the measured $\mathrm{pH}$. We subsequently challenged the sensors to measure the $\mathrm{pH}$ of unadulterated complex samples including cola, vinegar, serum, and urine, and obtained excellent agreement compared to a glass $\mathrm{pH}$ electrode. In addition to the positive analytical characteristics, the sensors are extremely cheap and easy to fabricate, making them highly accessible to a wide range of researchers. These results pave the way for customizable $\mathrm{pH}$ sensors that can be fabricated in (nearly) any geometry for targeted applications using 3D-printing.
\end{abstract}




\section{INTRODUCTION}

A system's pH influences reaction rates, stability, homeostasis, and chemical speciation, and is therefore one of the most fundamental descriptors of chemical, biological, and environmental samples.1-4 As a result measurement of $\mathrm{pH}$ is ubiquitous in many areas, for example water quality, 5 clinical measurements (e.g. blood and urine), 3 environmental monitoring, 6,7 and food safety. 8 While other techniques exist, $9,10 \mathrm{pH}$ is most often measured with a glass membrane electrode using potentiometry.11 While glass $\mathrm{pH}$ probes are widely used, they suffer from drawbacks including a need for frequent recalibration, difficulty in miniaturization, wet storage of the glass membrane, and interferences from alkali metals.6,11,12 Additionally, glass $\mathrm{pH}$ probes are delicate and require careful handling, making their use for in situ analyses difficult.

In response to these challenges, a number of groups have developed voltammetric $\mathrm{pH}$ sensors to overcome some of the limitations of potentiometric probes. Voltammetric $\mathrm{pH}$ sensors make use of surface-bound redox molecules, such as a quinones, that undergo a $\mathrm{pH}$-dependent reduction (Scheme 1).13 The $\mathrm{pH}$ of a solution is determined by the potential of the redox wave peak $(E \mathrm{p})$, which shifts towards more negative potentials as $\mathrm{pH}$ increases according to the Nernst Equation.14 There are two ways to introduce $\mathrm{pH}$-sensitivity to voltammetric $\mathrm{pH}$ probes: by chemically modifying the surface of an electrode with a pH-responsive chemical species 15,16 or by using the intrinsic functional groups on the surface of a carbon electrode. While both approaches generate excellent $\mathrm{pH}$-sensors, the latter approach is appealing because it does not require additional reagents or complex modification schemes. To date, a number of different carbon electrode materials have been employed for voltammetric $\mathrm{pH}$ sensing, including glassy carbon, 17 graphite, 18 carbon fibers, 19 screen printed electrodes, 20 and boron doped diamond (BDD).21-23 Furthermore, voltammetric $\mathrm{pH}$ sensing is attractive because the sensors can be calibrationless, 16 are easily miniaturized,22 and have excellent analytical performance compared with glass $\mathrm{pH}$ sensors. 24 However, one challenge with voltammetric $\mathrm{pH}$ sensors is that competing redox species can interfere with the measurements. Dissolved oxygen is the most likely interfering species in real samples and its presence require samples to be deoxygenated prior to analysis. 


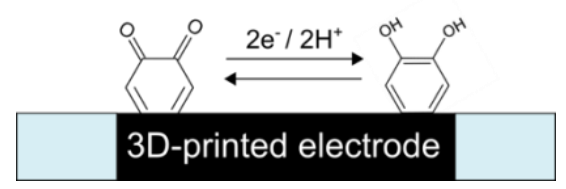

Scheme 1

Over the past decade, 3D-printed sensors and devices have seen tremendous growth, driven by their high performance, low cost, ease of fabrication, ability for customization, and potential for on-demand fabrication of customized sensors and devices.25-32 Their benefit is particularly attractive in scenarios where rapid prototyping or iterative design are desired and where highly customized one-of-a-kind sensors configurations are required. The most attractive materials for 3D-printed electrochemical sensors are commercially available graphene- or carbon blackcontaining thermoplastics, which have been used for a number of applications in energy storage26,33-37 and chemical sensing.38-45 These conductive thermoplastics are cheap and reliable electrode materials, but often require pretreatment to be useful for practical sensing applications because the conductive carbon is partially covered with plastic during the 3D-printing process.46,47 The reactivity of carbon electrodes is extremely complex and the surface pretreatment has a significant impact on the observed voltammetry by controlling the nature and concentration of functional groups on the electrode surface.48 While a number of pretreatment protocols have been proposed,43,44,46,47 they have mainly focused on preparing electrode surfaces for solution-based redox couples.

In this report, we developed 3D-printed voltammetric $\mathrm{pH}$ sensors using a commercially available graphene/poly(lactic acid) (PLA) filament by activating inherent quinone functional groups on the electrode surface. The important new result is that surface-bound quinone groups on the 3D-printed electrode enable robust $\mathrm{pH}$ sensing in complex media including undiluted foodstuffs, urine, and serum without interference from dissolved oxygen. The development of robust 3D-printed $\mathrm{pH}$ sensors is attractive because they can be designed for a variety of geometries, 49 easily integrated into flow-cells, 39 can be fabricated at the point of use, 30 are extremely inexpensive, and require no specialized equipment or expensive substrates. The critical step in the development of the sensors was the modification scheme to activate specific functional groups on the 3D-printed carbon surface to be useful for $\mathrm{pH}$ sensing without oxygen interference. 
We studied the effects of a three-step pretreatment protocol on the electrode surface using cyclic voltammetry (CV) and square wave voltammetry (SWV) and found that removal of the polymer coating, oxidation of the graphene surface, and conditioning the surface in buffer were critical for obtaining reproducible $\mathrm{pH}$ responses. After pretreatment, the sensors give Nernstian responses over the $\mathrm{pH}$ range from $\approx 2-11$ in buffer and, importantly, did not require oxygen to be removed prior to measurement, which has been a necessity for other carbon-based $\mathrm{pH}$-sensors (with the exception of lasered BDD pH sensors).23 We demonstrate the practical use of these sensors by measuring the $\mathrm{pH}$ of unadulterated horse serum, human urine, cola, and vinegar and observed only small differences when compared with a standard glass $\mathrm{pH}$-electrode. To our knowledge, this is the first example of voltammetric $\mathrm{pH}$ sensors being used in undiluted complex biological media. These results are important because they expand the scope of analytes measurable using 3Dprinted electrochemical sensors and demonstrate $\mathrm{pH}$ measurements in unadulterated biological samples and foodstuffs.

\section{EXPERIMENTAL}

Materials and Solutions. Hexaammineruthenium(III) chloride (98\%) was purchased from Acros Organics and used without purification. All other reagents were purchased from Fisher Scientific, were of ACS reagent grade or better, and used as received. Processed horse serum (New Zealand origin) was purchased from Gibco, aliquoted into $50 \mathrm{~mL}$ falcon tubes, and stored at $-80^{\circ} \mathrm{C}$ until use. White distilled vinegar (Goya) and cola (Coca-Cola) were obtained from local shops. Human urine was collected from a healthy male volunteer into a 250-mL Nalgene bottle. Carmody buffers were prepared as previous using two stock solutions.50 Solution A contained 0.2 M boric acid and $0.05 \mathrm{M}$ citric acid and solution B contained $0.1 \mathrm{M}$ sodium phosphate. The $\mathrm{pH}$ of all buffer solutions was measured with an Orion 5-Star benchtop $\mathrm{pH}$ meter with a glass membrane $\mathrm{pH}$ probe (ThermoFisher). Conductive graphene/PLA filament was purchased from BlackMagic3D (USA). All solutions were prepared using deionized water with resistivity of $18.2 \mathrm{M} \Omega \cdot \mathrm{cm}$ at $25^{\circ} \mathrm{C}$ (Millipore Simplicity).

Electrode Preparation and Fabrication. Figure 1 shows a schematic of the 3D-printed electrode geometry. We prepared graphene/PLA disk electrodes by extruding BlackMagic 3D printer filament through a $0.5 \mathrm{~mm}$ stainless steel nozzle into open air. Printing into open air prevents print orientation inconsistencies in which can impact the electrochemical properties 3D- 
printed sensors.51 The diameter of the printed filament is approximately $0.6 \mathrm{~mm}$ under the given settings (measured using digital calipers). We used two-part conductive silver epoxy (EpoTek) to make an electrical connection between the extruded filament and a $1 \mathrm{~mm}$ diameter copper wire. We sealed the $\mathrm{Cu}$ wire/3D-printed filament in a $100 \mu \mathrm{L}$ Eppendorf pipette tip with two-part insulating epoxy (JB Weld). We allowed the epoxy to cure overnight before cleaving the end to expose a fresh electrode surface using a clean razor blade. We then wet-sanded the electrodes using 600 and 1200 carbide sandpaper and polished using 1.0, 0.3, and $0.05 \mu \mathrm{m}$ alumina slurries.

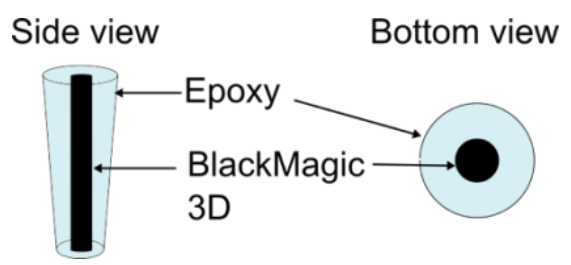

Figure 1: Schematic of 3D-printed pH sensor

Electrode Pretreatments. Once polished, we removed the excess PLA from the surface electrochemically by applying +1.4 and $-1.0 \mathrm{~V}$ in $0.5 \mathrm{M} \mathrm{NaOH}$ for 200 seconds each in two steps. 44 These electrodes were electrochemically active for inner-sphere redox species, but showed interference from dissolved oxygen using SWV. To remove the dissolved oxygen response, we used galvanostatic polarization to improve the $\mathrm{pH}$-sensitivity of the electrodes. To accomplish this, we applied $+0.1 \mathrm{~mA} \mathrm{~cm}-2(+36 \mu \mathrm{A})$ to the electrode in a strongly oxidizing electrolyte containing $2 \mathrm{M} \mathrm{H}_{2} \mathrm{SO}_{4}$ and $1 \mathrm{M} \mathrm{KNO}_{3}$. Representative polarization traces are for each electrochemical step are shown in Figure S1. In order to stabilize the surface chemistry of the electrode and prevent drift, we conditioned the electrodes in $\mathrm{pH} \approx 4$ Carmody buffer by running 1000 consecutive square wave voltammetry (SWV) runs.

Electrochemical Setup. All electrochemical experiments were conducted using either a $\mathrm{CH}$ Instruments $660 \mathrm{E}$ potentiostat or $760 \mathrm{E}$ bipotentiostat controlled using a desktop PC. All experiments were performed in a $20 \mathrm{~mL}$, three-electrode cell using a saturated calomel electrode reference electrode ( $\mathrm{CH}$ instruments) and $\mathrm{Pt}$ wire counter ( $\mathrm{CH}$ instruments). $\mathrm{pH}$ was measured using square wave voltammetry $(\mathrm{SWV})$ from +0.5 to $-0.5 \mathrm{~V}$ with the following parameters: $E_{\text {step }}=$ $0.004 \mathrm{~V}$, amplitude $=0.025 \mathrm{~V}$, and frequency $=100 \mathrm{~Hz}$. The overall scan rate was $0.4 \mathrm{~V} \mathrm{~s}-1$. Linear background subtraction of SWVs was performed using the peak analysis tool in Origin. 


\section{RESULTS AND DISCUSSION}

Development of pH-sensitive surface oxides on graphene/PLA electrodes. The major challenge in developing voltammetric $\mathrm{pH}$ sensors using 3D-printed graphene/PLA was to develop a protocol to activate $\mathrm{pH}$-sensitive functional groups (e.g. quinones) on to the surface of the graphene/PLA.47 To accomplish this, we prepared disk electrodes by sealing $0.6 \mathrm{~mm}$ diameter extruded graphene/PLA in a pipette tip using araldite epoxy (see Experimental section for details). We used a multi-step procedure to activate the 3D-printed surfaces for $\mathrm{pH}$ sensing. First, we wetsanded the electrodes using 600 and 1200 carbide sandpaper and polished using 1.0, 0.3, and 0.05

$\mu \mathrm{m}$ alumina slurries with copious rinsing after each step. Second, we removed excess PLA from the surfaces by applying +1.4 and $-1.0 \mathrm{~V}$ vs. $\mathrm{Ag} / \mathrm{AgCl}$ for 200 s each in $0.5 \mathrm{M} \mathrm{NaOH}$ while stirring with a magnetic flea at $1000 \mathrm{rpm} .52$ Third, we polarized the electrodes galvanostatically in an electrolyte containing $2 \mathrm{M} \mathrm{H}_{2} \mathrm{SO}_{4}$ and $1 \mathrm{M} \mathrm{KNO}_{3}$ with $+0.1 \mathrm{~mA} \mathrm{~cm}-2(+36 \mu \mathrm{A})$ for $60 \mathrm{~s}$. Representative data for the electrochemical pretreatments can be found in the supporting information Figure S1.

In order to determine how the electrochemically active surfaces were physically and chemically changing during these pretreatment steps, we performed $\mathrm{CV}$ using $\mathrm{Ru}\left(\mathrm{NH}_{3}\right)_{63}+$ and $\mathrm{Fe}(\mathrm{CN}) 63$ - and interrogated the intrinsic $\mathrm{pH}$-sensitivity of the modified surfaces using $\mathrm{SWV}$ in Carmody buffer solutions. $\mathrm{Ru}\left(\mathrm{NH}_{3}\right) 63+$ was selected because it is an outer-sphere redox couple and is insensitive to changes in the electrode surface, but is sensitive to changes in electroactive area. 48 $\mathrm{Fe}(\mathrm{CN}) 63$ - is an inner-sphere couple and is sensitive to changes in both the electrode surface and area.48 SWV was used to detect the presence of quinone groups on the electrode surface.53 These three redox probes allow us to understand how the surface area changes, elucidate changes in surface reactivity, and determines which surfaces are suitable for $\mathrm{pH}$ measurements.

The first step in the activation procedure is wet sanding with 600 and 1200 grit sandpaper followed by polishing with alumina slurries $(1.0,0.3$, and $0.05 \mu \mathrm{m})$. The black traces in Figure $2 \mathrm{a}$ and 2 b show $\mathrm{CV}$ s taken in $\mathrm{Ru}\left(\mathrm{NH}_{3}\right)_{63}+$ and $\mathrm{Fe}(\mathrm{CN})_{63-}$, respectively. The $\mathrm{CV}$ in $\mathrm{Ru}\left(\mathrm{NH}_{3}\right)_{63}+$ shows quasi-reversible behavior $(\Delta E \mathrm{p} \approx 103 \mathrm{mV})$ with a peak current ratio $\left(i_{\mathrm{p}, \mathrm{c}} / i_{\mathrm{p}, \mathrm{a}}\right)$ close to 1 . $\mathrm{Ru}\left(\mathrm{NH}_{3}\right)_{63+}$ is known to have fast heterogeneous electron transfer (HET) kinetics on pristine graphene/graphite electrodes,54 but on these materials HET is impeded significantly. Note that the $\Delta E \mathrm{p}$ for a reversible electrochemical reaction is $\approx 60 \mathrm{mV}$ for a one electron reduction. CVs obtained in 
$\mathrm{Fe}(\mathrm{CN})$ 63- show no detectable redox activity (Figure 2b, black trace). Our interpretation of these data is that the relatively low loading of carbon in the filament leaves only a small number of active conductive particles on the electrode surface. These conductive particles are active for the outersphere reduction of $\mathrm{Ru}(\mathrm{NH} 3) 63+$, but not for the inner-sphere $\mathrm{Fe}(\mathrm{CN}) 64$ - reduction. These data are consistent with previous reports using a similar activation procedure.43,44

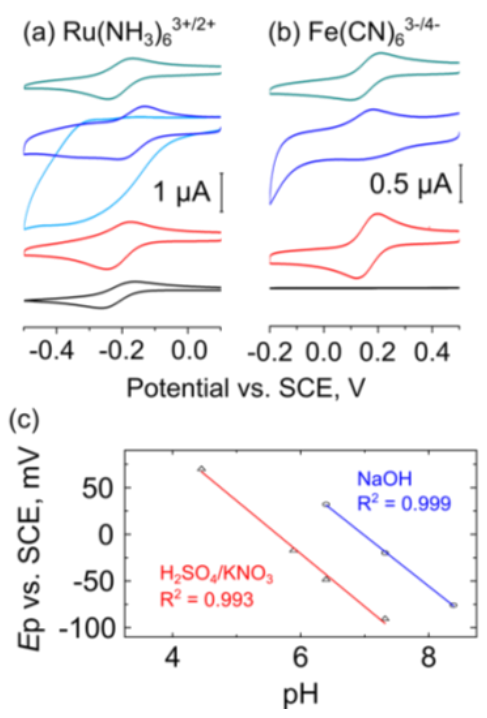

Figure 2: Electrochemical characterization of electrochemical pretreatment steps using $\mathrm{Ru}\left(\mathrm{NH}_{3}\right)_{63+}, \mathrm{Fe}(\mathrm{CN})_{63-}$, and $\mathrm{pH}$. (a) $\mathrm{CVs}$ of pretreated electrodes in $\mathrm{Ru}\left(\mathrm{NH}_{3}\right)_{63+}$; (b) $\mathrm{CVs}$ of pretreated electrodes in $\mathrm{Fe}(\mathrm{CN}) 63$ - Color scheme for (a) and (b): Black - alumina polished; red $\mathrm{NaOH}$ activation; blue $-\mathrm{H}_{2} \mathrm{SO}_{4}$ activation; cyan - after $1000 \mathrm{SWV}$ cycles in $\mathrm{pH} 4$ Carmody buffer. Scan rate: $0.1 \mathrm{~V} \mathrm{s-1}$; (c) $\mathrm{pH}$ calibrations for electrodes treated with $\mathrm{NaOH}$ and $\mathrm{H}_{2} \mathrm{SO}_{4} / \mathrm{KNO}_{3}$.

We investigated the $\mathrm{pH}$ response of the polished graphene/PLA electrodes using SWV in Carmody buffers over the potential range from +1 to $-1 \mathrm{~V}$ (Figure $\mathrm{S} 2 \mathrm{a}$ ). The voltammograms show small peaks in the range of $\pm 0.5 \mathrm{~V}$. Figure $3 \mathrm{~b}$ shows a plot of the main peak in each $\mathrm{SWV}$ trace versus the $\mathrm{pH}$ of the buffer solution. The data shows a contra-Nernstian increase in peak potential as $\mathrm{pH}$ is increased from 2.02 to 6.36 before leveling off at $\mathrm{pHs}$ greater than 6.37 . These data suggest that polishing the graphene/PLA electrode does not develop $\mathrm{pH}$-sensitive functional groups and demonstrates the need for additional electrode pretreatment.

The second step in our activation procedure is to remove the passivating PLA using $\mathrm{NaOH}$, which was chosen based on recent results from Richter et al. and Kalinke et al.44,47 $\mathrm{NaOH}$ activates 
the filaments by saponification of the aliphatic ester groups in PLA, thus exposing more of and also activating the graphene fibers.52 After activation in $\mathrm{NaOH}$, we observed significant improvements in the voltammetry for both redox couples (red traces in Figure 2). HET kinetics of $\mathrm{Ru}\left(\mathrm{NH}_{3}\right)_{63}+$ reduction improve significantly as evidenced by the decrease in $\Delta E \mathrm{p}(\approx 68 \mathrm{mV}$ after activation) compared with the polished electrode.44 In $\mathrm{Fe}(\mathrm{CN}) 63-$, the emergence of a well-defined voltammogram demonstrates that the exposed carbon surface is activated by $\mathrm{NaOH}$ treatment. HET kinetics for $\mathrm{Fe}(\mathrm{CN}) 63$ - reduction are relatively fast $(\Delta E \mathrm{p} \approx 78 \mathrm{mV})$ and the peak current ratio is also close to 1 , suggesting chemical reversibility. $\mathrm{In} \mathrm{Ru}\left(\mathrm{NH}_{3}\right)_{63+}$, the cathodic peak height $\left(i_{\mathrm{p}, \mathrm{c}}\right)$ increases $\approx 1$.6x for after activation in $\mathrm{NaOH}$ compared to the polished electrode due to an increase in electroactive area. Previous electron microscopy results have shown that there is a significant increase in the amount of exposed carbon after $\mathrm{NaOH}$ treatment,44,47 which is consistent with the results here. Taken together, these data suggest that the $\mathrm{NaOH}$ pretreatment effectively removes PLA from the graphene surface and activates the graphene, thus enabling more facile electron transfer.

In order to determine if the $\mathrm{NaOH}$ activation induced $\mathrm{pH}$-sensitive surface oxides, we performed SWV in Carmody buffers over the potential range from +0.5 to $-0.5 \mathrm{~V}$. The SWVs in Figure S3a show small peaks in the region of $0.0 \pm 0.1 \mathrm{~V}$ vs. SCE that are $\mathrm{pH}$ dependent. Figure 2c (blue trace) shows a plot of the $\mathrm{pH}$-dependent peak around $0.0 \mathrm{~V}$ as a function of $\mathrm{pH}$ using the $\mathrm{NaOH}$ pretreated electrode. After polarization in $\mathrm{NaOH}$, waves from the reduction of $\mathrm{pH}$ dependent species were observed that had a near-Nernstian $\mathrm{pH}$ dependence (gradient $=-54.2 \pm$ $0.1 \mathrm{mV}$ pH-1; $\left.R_{2}=0.999\right)$. The SWVs in Figure S3a also show a large secondary peak with a position that was independent of $\mathrm{pH}$ at ca. $-0.3 \mathrm{~V}$. The secondary peak decreased linearly with deaeration time after bubbling with Ar for over the course of 30 minutes (Figure $\mathrm{S} 4 ; R_{2}=0.989$ ), and thus we assign this secondary peak to the oxygen reduction reaction (ORR). Interestingly, the ORR peak intensity was present even after 30 minutes of vigorous Ar bubbling. While these results were encouraging, the large interference from ORR was problematic because it would require deaerating samples prior to analysis, leading to additional processing steps for real samples and making in situ measurements without oxygen interference impossible.

We subsequently investigated galvanostatic polarization using a very oxidizing acidic electrolyte (2 $\mathrm{M} \mathrm{H}_{2} \mathrm{SO}_{4} / 1 \mathrm{M} \mathrm{KNO}_{3}$ ) with the aim of decreasing the influence of the ORR peak. After galvanostatic polarization in $\mathrm{H}_{2} \mathrm{SO}_{4} / \mathrm{KNO}_{3}$, the $\mathrm{Ru}\left(\mathrm{NH}_{3}\right)_{63+}$ signal is obscured by the 
presence of a large redox wave (Figure 2a, light blue trace), which we assign to the reduction of surface-oxides generated during anodic polarization. The presence of this new reduction wave indicates the encouraging presence of fully-oxidized quinones on the surface of the electrode.55-57 The intensity of the large reduction wave decreases with subsequent $\mathrm{CV}$ cycling, revealing a $\mathrm{Ru}\left(\mathrm{NH}_{3}\right)_{63}+\mathrm{CV}$ similar to the $\mathrm{NaOH}$ treated electrode (Figure 2a, blue trace). The $\mathrm{Fe}(\mathrm{CN})_{63}$ - signal has a significantly higher background current and $\Delta E \mathrm{p}$ decreases to $\approx 32 \mathrm{mV}$. This suggests that either $\mathrm{Fe}(\mathrm{CN}) 63$ - is either adsorbing to the graphenes8 or thin-layer electrochemical behavior is occurring. 14 We are currently undertaking a more thorough study on this system and will report the results in due course.

Figure S3b shows representative $\mathrm{SWVs}$ of a $\mathrm{H}_{2} \mathrm{SO}_{4} / \mathrm{KNO}_{3}$-treated electrode in Carmody buffers. Interestingly, in these solutions the secondary peak at $-0.3 \mathrm{~V}$ disappeared (Figure S3b) demonstrating that the surfaces are no longer sensitive to dissolved oxygen. After galvanostatic polarization, the gradient of the $\Delta E \mathrm{p}$ vs. $\mathrm{pH}$ curve remained near-Nernstian at $25^{\circ} \mathrm{C}$ (gradient $=-$ $56.6 \pm 0.3 \mathrm{mV} \mathrm{pH}-1 ; R_{2}=0.993$ ), but the peaks shifted towards more cathodic potentials compared with the $\mathrm{NaOH}$-only samples. This shift suggests that the galvanostatic polarization imparts a very different surface chemistry compared with the $\mathrm{NaOH}$ treatment.

During repeated $\mathrm{pH}$-measurements of the $\mathrm{H}_{2} \mathrm{SO}_{4} / \mathrm{KNO}_{3}$-treated sensors, we observed a problematic drift in peak potential and an increase in peak current as we made replicate measurements. We studied this systematically by performing $1000 \mathrm{SWV}$ from +0.5 to $-0.5 \mathrm{~V}$ in pH 4 Carmody buffer to determine how stable quinone reduction was on the 3D-printed electrode surface. Figure 3ai shows scans 10-100 (in increments of 10) and Figure 3aii shows scans 1001000 (in increments of 100), showing very reproducible SWVs over the 1000 cycles. Each set of voltammograms displays a single wave centered near $+0.13 \mathrm{~V}$ vs. SCE that appears to grow with increasing cycles. We integrated the SWVs to determine the charge passed during quinone reduction and converted charge to surface coverage, $\Gamma(\mathrm{nmol} \mathrm{cm}-2)$, using eq. 1 :

$$
\Gamma=\frac{q}{n A F}
$$

where $q$ is the charge passed (in C), $n$ is the number of electrons passed during reduction (=2), $A$ is the electrode area $(=1.3 \cdot 10-3 \mathrm{~cm} 2)$, and $F$ is Faraday's constant (96485 C mol-1). Figure $3 \mathrm{~b}$ shows that $\Gamma$ increases with increasing scan number up until $\approx 200$ scans, after which $\Gamma$ stabilizes at $2.84 \pm 0.2 \mathrm{nmol} \mathrm{cm}-2$ (mean $\pm s ; n=17)$. Over the first 10 cycles, $\Gamma$ increases linearly $\left(R_{2}=\right.$ 
0.9972; Figure $3 \mathrm{~b}$ inset) and reaches $90 \%$ of the maximum value after 80 scans. BatchelorMcAuley et al. reported that monolayers of anthraquinone on edge plane pyrolytic graphite had have surface coverage of $2.5 \mathrm{nmol} \mathrm{cm}-2.59$ However, previously reported quinone-based $\mathrm{pH}$ sensors had surface coverages that were 2-4 orders of magnitude lower than those reported here.18,23 We suspect that the high surface coverage in our sensors arises because of an increased electroactive surface area (as exemplified in the $\mathrm{Ru}\left(\mathrm{NH}_{3}\right)_{63}+\mathrm{CV}$ s in Figure 2a) and a high number of quinone functional groups developed during the anodic polarization in $\mathrm{H}_{2} \mathrm{SO}_{4} / \mathrm{KNO}_{3}$.
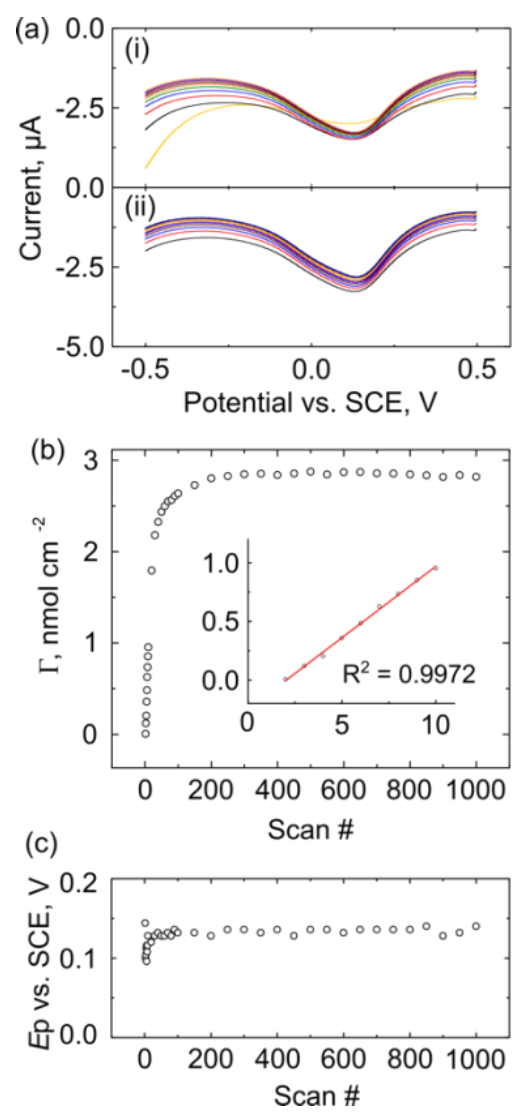

Figure 3: 3D-printed voltammetric $\mathrm{pH}$ sensors require conditioning before stable measurements are achieved. (a) SWV traces of electrode conditioning in $\mathrm{pH} 3.97$ Carmody buffer. (i) conditioning traces 10-100 in 10 scan increments and (ii) 100-1000 in 100 scan increments. (b) Plot of quinnone surface coverage as a function of scan number. Inset shows the first 10 scans, where the increase in surface coverage is linear. (c) Plot of quinone reduction peak center $(E \mathrm{p})$ versus scan number. 
$E \mathrm{p}$ is used to determine solution $\mathrm{pH}$ and drift would lead to systematic error in $\mathrm{pH}$ measurement of unknown samples. During the 1000 SWV cycles, Ep shifted towards more positive potentials over the initial scans, but stabilized after only thirty cycles (Figure 3c). After the 30th cycle, Ep was $0.133 \pm 0.004 \mathrm{~V}$ vs. SCE $(n=26)$ and remained stable for over 900 scans. This result highlights the importance of the pretreatment protocol and demonstrates the stability of the $\mathrm{pH}$ measurement after conditioning. After the $1000 \mathrm{SWV}$ cycles, we measured CVs in $\mathrm{Ru}\left(\mathrm{NH}_{3}\right)_{63+}$ and $\mathrm{Fe}(\mathrm{CN}) 63$ - to see how the surfaces were impacted by continuous cycling (Figure $2 \mathrm{a}$ and $2 \mathrm{~b}$, dark cyan traces). For $\mathrm{Ru}\left(\mathrm{NH}_{3}\right)_{63+}, \Delta E \mathrm{p}$ increased slightly from 68 to $76 \mathrm{mV}$ while the peak current decreased to $\approx 78 \%$ of the value (compared with the $\mathrm{NaOH}$ treated electrode). For $\mathrm{Fe}(\mathrm{CN}) 63-, \Delta E \mathrm{p}$ increased from 78 to $112 \mathrm{mV}$ and the peak current decreased to $74 \%$ of the value. pH response of $3 D$ printed sensors. After demonstrating the presence of surface-bound quinones on the graphene/PLA electrodes, we turned our attention to investigating the $\mathrm{pH}$ response of the sensors over a broad $\mathrm{pH}$ range. In order to assess the working $\mathrm{pH}$ range of the sensors, we performed SWV over the potential range from +0.5 to $-0.5 \mathrm{~V}$ vs. SCE using $\mathrm{pH} 2.02-11.22$ Carmody buffers. Each electrode was pretreated using the procedure outlined above, including cycling for $1000 \mathrm{SWV}$ s between +0.5 and $-0.5 \mathrm{~V}$ at $0.4 \mathrm{~V} \mathrm{~s}-1$ which increased the peak intensity and stabilized the peak position. We note that each electrode only required cycling once and that the peak potentials and intensities remained stable indefinitely.

Figure 4a shows representative SWVs collected over this range. Each trace shows a large, well-defined redox peak associated with the reduction of surface-bound quinone groups. Note the significant increase in signal compared with Figures S2 and S3 due to the activation of quinones on the surface during repeated cycling. The positions of the quinone reduction peaks are fully consistent with the range of quinone reductions previously reported, giving confidence that the species being reduced on the surface are in fact quinone groups.17,18,20,23 The position of the peak potential $\left(E_{\mathrm{p}}\right)$ shifts to more negative potentials as the $\mathrm{pH}$ of the buffer is increased, which is consistent with a $2 \mathrm{e}-12 \mathrm{H}_{+}$proton coupled electron transfer (PCET) mechanism expected for quinone reduction.13 To reiterate, control experiments performed without pretreating the graphene/PLA electrode showed no detectable quinone reduction peaks within the scan window (Figure S2), demonstrating the importance of the multi-step pretreatment protocol.

Figure $4 \mathrm{~b}$ shows a plot of the peak potential versus the solution $\mathrm{pH}$ for three independent electrodes that were prepared identically and pretreated using the protocol described above. All 
three sensors have wide linear ranges from $\mathrm{pH} 2.02-11.22$ with excellent linearity $\left(R_{2} \geq 0.99\right.$ for all sensors). The sensors have an average gradient of $-60 \pm 2 \mathrm{mV} \mathrm{pH}-1(n=3$; individual slopes shown in Figure $4 b$ ), which is in excellent agreement with the expected value of $-59 \mathrm{mV} \mathrm{pH}-1$ (calculated using the Nernst Equation). The data in Figure $4 \mathrm{~b}$ demonstrate the reproducibility of the fabrication and electrochemical pretreatment procedure. It is important to note that all of the data in Figure 4 was recorded without degassing the solution, which was a requirement for previous pH sensors using graphite, glassy carbon, and SPEs.17,18,20 Oxygen is a problematic interferent for voltammetric $\mathrm{pH}$ sensors because it is present at relatively high concentrations in real samples $(\approx 0.25 \mathrm{mM}$ at room temperature).60 Although quinone groups are known to catalytically reduce oxygen,55-57 we see no evidence of oxygen reduction within the scan window after the pretreatment.
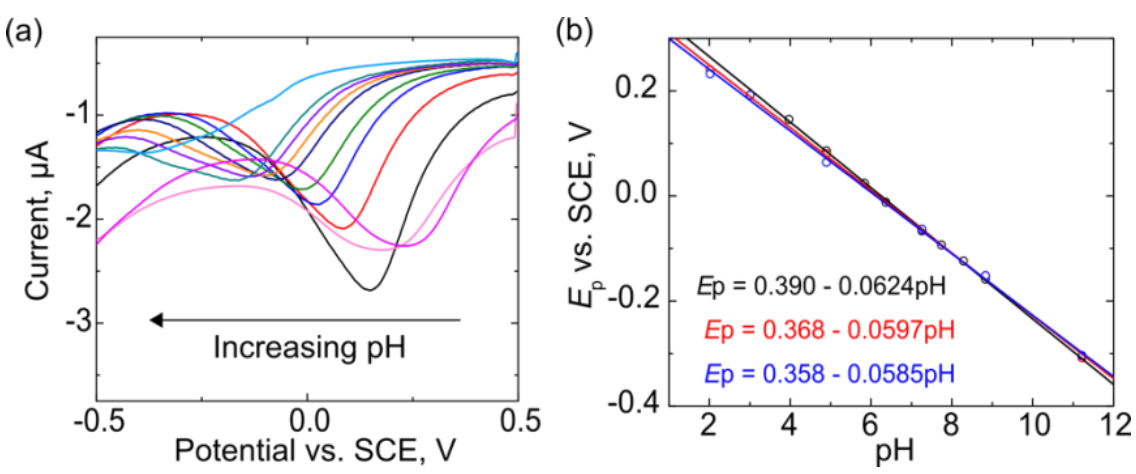

Figure 4: 3D-printed voltammetric $\mathrm{pH}$ sensors show a Nernstian $\mathrm{pH}$-shift. (a) Representative SWV traces of quinone reduction in Carmody buffers over the $\mathrm{pH}$ range from 2.02-11.22. SWV voltammetry data was smoothed using a 7 point Savitsky-Golay function; (b) Plot of reduction peak potential versus $\mathrm{pH}$ showing a Nernstian response. Error bars for three replicate measurements are smaller than the symbols.

In order to determine the utility of these sensors in real-world applications, we first attempted to measure $\mathrm{pH}$ in the presence of additional redox species commonly found in contaminated environmental samples, using the heavy metals $\mathrm{Pb}_{2}+$ and $\mathrm{Cu}_{2}+$ as examples. $\mathrm{Pb}_{2+}$ and $\mathrm{Cu}_{2+}$ have formal potentials within the scan window and therefore could deposit on the surface of the sensor if present in an environmental sample. Figure 5 shows the impact of $\mathrm{Pb}_{2+}$ and $\mathrm{Cu}_{2+}$ on the $\mathrm{pH}$ response of our sensors. SWV traces (average of 10 measurements using one sensor) for 
pH 4.40 Carmody buffer (black trace) show a single peak with Ep near $0.17 \mathrm{~V}$ vs. SCE. The sample was then fortified with $100 \mu \mathrm{M} \mathrm{Pb}_{2+}$ (red trace) followed by $100100 \mu \mathrm{M} \mathrm{Cu}_{2+}$ (blue trace), but there was virtually no change to the position of the main peak at $0.17 \mathrm{~V}$. After fortifying with 100 $\mu \mathrm{M} \mathrm{Cu}_{2+}$, a small shoulder appeared on the main peak around $-0.17 \mathrm{~V}$, but this had no impact on the main peak and would therefore not impact the measured $\mathrm{pH}$. Note that the concentrations of heavy metals used in this experiment are orders of magnitude larger than what is expected in environmental samples (unless in the case of extreme contamination), yet the SWVs show no deviation in peak potential after the addition of these metals. This result shows that the presence of high concentrations of $\mathrm{Pb}_{2+}$ and $\mathrm{Cu}_{2}+$ does not impact $\mathrm{pH}$ measurements using this sensor.

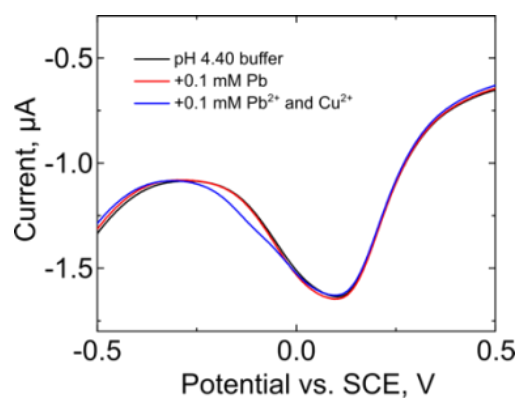

Figure 5: SWVs of $\mathrm{pH} 4.40$ Carmody buffer (black trace) fortified with $0.1 \mathrm{mM} \mathrm{Pb} 2+$ (red trace) and $0.1 \mathrm{mM} \mathrm{Pb}_{2+}$ and $\mathrm{Cu}_{2+}$. All traces are an average of ten independent measurements recorded with one sensor.

To determine if complex matrices impact the performance of the graphene/PLA $\mathrm{pH}$ sensors, we further challenged them to unadulterated samples spanning a range of applications including foodstuffs (vinegar and cola) and complex biological samples (urine and horse serum). Figure 6 shows representative SWVs for each of these complex samples. Note that for all measurements in Figure 6 there was no dilution, addition of salts, or deaeration of the samples. In each case, a well-defined quinone reduction wave was observed that is qualitatively similar to what was observed in buffered solutions. By comparing the vinegar and cola data, it is clear that the complex sample matrix in the cola (which includes caffeine, sugars, dyes, and other additives) does not impact the reduction of surface-bound quinnones (Figure S5 for direct comparison of the two SWVs). We note that in the unadulterated biological samples, the peaks were somewhat broader than observed in buffer and in urine there was a broad wave between +0.3 and $+0.5 \mathrm{~V}$, which does not impact the $\mathrm{pH}$ peak. We used the buffer calibration curve for this sensor (Figure 
4b) to determine the $\mathrm{pH}$ of each sample and compared the value with a standard glass $\mathrm{pH}$ probe, which is the standard method for measuring $\mathrm{pH}$. Figure $6 \mathrm{~b}$ shows a bar graph comparing the graphene/PLA $\mathrm{pH}$ electrode and a glass $\mathrm{pH}$ probe (ThermoOrion) and demonstrates excellent agreement between the graphene/PLA pH sensor and the glass $\mathrm{pH}$ electrode. The percent errors for vinegar, cola, urine, and serum were $2.0 \%, 1.8 \%, 3.2 \%$, and $4.1 \%$, respectively (Table S1). These data show that these sensors have significant potential for performing real measurements in complex samples.
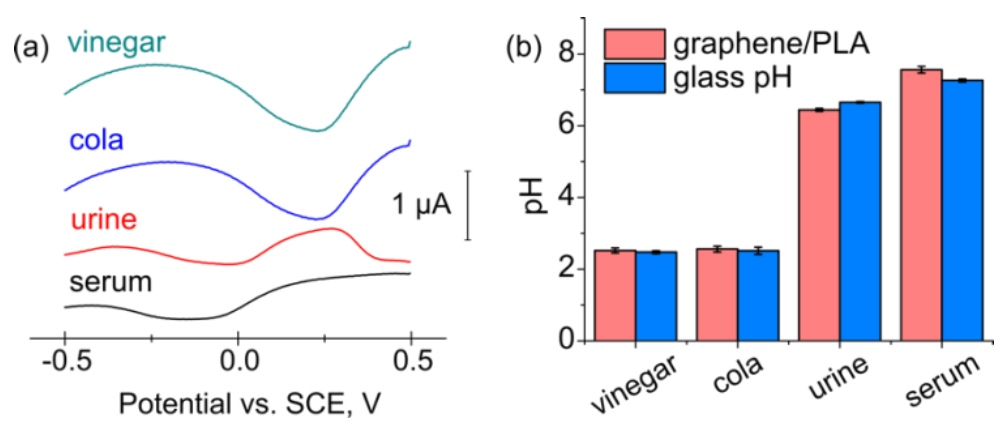

Figure 6: (a) Representative SWV traces of a 3D-printed voltammetric $\mathrm{pH}$ sensor in undiluted real samples; (b) bar graph comparing the $\mathrm{pH}$ responses of the graphene/PLA sensor to a glass $\mathrm{pH}$ probe. Table S1 in the supporting information presents the data from the bar graph in Table form.

The performance of the $\mathrm{pH}$ sensors described herein is in excellent agreement with previously reported $\mathrm{pH}$ sensors developed using more traditional carbon electrodes.17-23 Galdino et al. used screen printed graphite electrodes to measure malt vinegar and antacid tablets. They measured differences of 0.12 and $0.35 \mathrm{pH}$ units for the malt vinegar and antacid, respectively,20 which is slightly more than we measured with our 3D-printed sensors $(0.05 \mathrm{pH}$ units in both vinegar and soda). The Macpherson group employed a lasered BDD $\mathrm{pH}$ sensor to measure seawater23 and a dilute (1:1) Sheep's blood/Alsever's solution media.24 The results in seawater were within $0.01 \mathrm{pH}$ units while the Sheep's blood/Alsever's solution was within $0.22 \mathrm{pH}$ units of a standard glass $\mathrm{pH}$ probe. These results are similar to what we observe with our electrodes $(0.30$ $\mathrm{pH}$ units in horse serum), which did not require dilution prior to analysis. 


\section{CONCLUSIONS}

In this report, we described the preparation and application of voltammetric $\mathrm{pH}$ sensors based on graphene/PLA 3D-printed filament. The key to this work is the electrode pretreatment procedure, which enabled reliable and consistent $\mathrm{pH}$ measurements to be made over a wide $\mathrm{pH}$ range $(\approx 2-11)$. We used electrochemical characterization to track the changes in the sensors electroactive area and redox activity during pretreatment and found that all three steps were imperative to performing robust and reliable $\mathrm{pH}$ measurements over a wide $\mathrm{pH}$ range. An important feature of the $\mathrm{pH}$ sensors described here is that samples do not require oxygen removal prior to analysis, greatly simplifying sample pretreatment and making possible in situ measurements. We subsequently used the sensors to analyze complex food and biological samples without having to modify the samples using dilution, addition of salt, or degassing. These results are important because they expand the scope of analytes measurable using 3D-printed electrochemical sensors and demonstrate $\mathrm{pH}$ measurements in unadulterated biological samples and foodstuffs. In addition to the positive analytical characteristics, the sensors are extremely cheap and easy to fabricate, making them highly accessible to a wide range of researchers. These results pave the way for customizable $\mathrm{pH}$ sensors that can be fabricated in (nearly) any geometry for targeted applications using 3D-printing.

\section{ACKNOWLEDGEMENTS}

We thank the New Jersey Space Grant Consortium (FMR) and Montclair State University for financial support of this work.

\section{REFERENCES}

(1) Ledezma-Yanez, I.; Wallace, W. D. Z.; Sebastián-Pascual, P.; Climent, V.; Feliu, J. M.; Koper, M. T. M. Nat. Energy 2017, 2, 17031.

(2) Masscheleyn, P. H.; Delaune, R. D.; Patrick, W. H. Environ. Sci. Technol. 1991, 25, 14141419.

(3) Hamm, L. L.; Nakhoul, N.; Hering-Smith, K. S. Clin. J. Am. Soc. Nephrol. 2015, 10, 22322242. 
(4) National Research Council. Ocean Acidification: A National Strategy to Meet the Challenges of a Changing Ocean.; The National Academies Press: Washington, DC, 2010.

(5) Qin, Y.; Alam, A. U.; Pan, S.; Howlader, M. M. R.; Ghosh, R.; Hu, N.-X.; Jin, H.; Dong, S.; Chen, C.-H.; Deen, M. J. Sensors Actuators B Chem. 2018, 255, 781-790.

(6) Dickson, A. G. Mar. Chem. 1993, 44, 131-142.

(7) Orr, J. C.; Fabry, V. J.; Aumont, O.; Bopp, L.; Doney, S. C.; Feely, R. A.; Gnanadesikan, A.; Gruber, N.; Ishida, A.; Joos, F.; Key, R. M.; Lindsay, K.; Maier-Reimer, E.; Matear, R.; Monfray, P.; Mouchet, A.; Najjar, R. G.; Plattner, G.-K.; Rodgers, K. B.; Sabine, C. L.; Sarmiento, J. L.; Schlitzer, R.; Slater, R. D.; Totterdell, I. J.; Weirig, M.-F.; Yamanaka, Y.; Yool, A. Nature 2005, 437, 681-686.

(8) Patel, P. D. TrAC - Trends Anal. Chem. 2002, 21 (2), 96-115.

(9) Wencel, D.; Abel, T.; McDonagh, C. Anal. Chem. 2014, 86, 15-29.

(10) Frankær, C. G.; Sørensen, T. J. ACS Omega 2019, 4, 8381-8389.

(11) Kraikaew, P.; Soda, Y.; Cherubini, T.; Bakker, E. ACS Sensors 2020, doi:10.1021/acssensors.0c00031.

(12) Bühlmann, P.; Pretsch, E.; Bakker, E. Chem. Rev. 1998, 98 (4), 1593-1688.

(13) Cobb, S. J.; Ayres, Z. J.; Newton, M. E.; Macpherson, J. V. J. Am. Chem. Soc. 2019, 141, 1035-1044.

(14) Bard, A. J.; Faulkner, L. R. Electrochemical Methods: Fundamentals and Applications, Second Edi.; John Wiley \& Sons, Inc.: New York, 2001.

(15) Amiri, M.; Amali, E.; Nematollahzadeh, A.; Salehniya, H. Sensors Actuators B. Chem. 2016, 228, 53-58.

(16) Xiong, L.; Batchelor-McAuley, C.; Compton, R. G. Sensors Actuators B. Chem. 2011, 159, 251-255.

(17) Lu, M.; Compton, R. G. Analyst 2014, 139, 4599-4605.

(18) Lu, M.; Compton, R. G. Analyst 2014, 139, 2397-2403.

(19) Makos, M. A.; Omiatek, D. M.; Ewing, A. G.; Heien, M. L. Langmuir 2010, 26, 1038610391.

(20) Galdino, F. E.; Smith, J. P.; Kwamou, S. I.; Kampouris, D. K.; Iniesta, J.; Smith, G. C.; Bonacin, J. A.; Banks, C. E. Anal. Chem. 2015, 87, 11666-11672.

(21) Fierro, S.; Mitani, N.; Comninellis, C.; Einaga, Y. Phys. Chem. Chem. Phys. 2011, 13 (37), 16795-16799.

(22) Silva, E. L.; Bastos, A. C.; Neto, M. a.; Silva, R. F.; Ferreira, M. G. S.; Zheludkevich, M. 
L.; Oliveira, F. J. Electrochem. Commun. 2014, 40, 31-34.

(23) Ayres, Z. J.; Borrill, A. J.; Newland, J. C.; Newton, M. E.; Macpherson, J. V. Anal. Chem. 2016, 88, 974-980.

(24) Read, T. L.; Cobb, S. J.; Macpherson, J. V. ACS Sensors 2019, 4, 756-763.

(25) Symes, M. D.; Kitson, P. J.; Yan, J.; Richmond, C. J.; Cooper, G. J. T.; Bowman, R. W.; Vilbrandt, T.; Cronin, L. Nat. Chem. 2012, 4 (5), 349-354.

(26) Browne, M. P.; Redondo, E.; Pumera, M. Chem. Rev. 2019.

(27) Cocovi-Solberg, D. J.; Worsfold, P. J.; Miró, M. TrAC - Trends Anal. Chem. 2018, 108, 1322.

(28) Ni, Y.; Ji, R.; Long, K.; Bu, T.; Chen, K.; Zhuang, S. Appl. Spectrosc. Rev. 2017, 10.1080/05704928.2017.1287082.

(29) Ambrosi, A.; Pumera, M. Chem. Soc. Rev. 2016, 45 (10), 2740-2755.

(30) O'Neil, G. D. Curr. Opin. Electrochem. 2020, 20, 60-65.

(31) Abdalla, A.; Patel, B. A. Curr. Opin. Electrochem. 2020, 20, 78-81.

(32) Cardoso, R. M.; Kalinke, C.; Rocha, R. G.; dos Santos, P. L.; Rocha, D. P.; Oliveira, P. R.; Janegitz, B. C.; Bonacin, J. A.; Richter, E. M.; Munoz, R. A. A. Anal. Chim. Acta 2020, $1118,73-91$.

(33) O’Neil, G. D.; Christian, C. D.; Brown, D. E.; Esposito, D. V. J. Electrochem. Soc. 2016, 163, F3012-F3019.

(34) Talabi, O. O.; Dorfi, A. E.; O’Neil, G. D.; Esposito, D. V. Chem. Commun. 2017, 53, 80068009.

(35) Browne, M. P.; Plutnar, J.; Pourrahimi, A. M.; Sofer, Z.; Pumera, M. Adv. Energy Mater. 2019, 9, 1900994.

(36) Ambrosi, A.; Pumera, M. ACS Sustain. Chem. Eng. 2018, 6, 16968-16975.

(37) Chisholm, G.; Kitson, P. J.; Kirkaldy, N. D.; Bloor, L. G.; Cronin, L. Energy Environ. Sci. 2014, 7, 3026-3032.

(38) Rymansaib, Z.; Iravani, P.; Emslie, E.; Medvidović-Kosanović, M.; Sak-Bosnar, M.; Verdejo, R.; Marken, F. Electroanalysis 2016, 28 (7), 1517-1523.

(39) O’Neil, G. D.; Ahmed, S.; Halloran, K.; Janusz, J. N.; Rodríguez, A.; Terrero Rodríguez, I. M. Electrochem. Commun. 2019, 99, 56-60.

(40) Walters, J. G.; Ahmed, S.; Terrero Rodríguez, I. M.; O’Neil, G. D. Electroanalysis 2020, $32,859-866$.

(41) Skaria, E.; Patel, B. A.; Flint, M. S.; Ng, K. W. Anal. Chem. 2019, 91, 4436-4443. 
(42) Patel, N.; Fagan-murphy, A.; Covill, D.; Patel, B. A. Anal. Chem. 2017, 10.1021/acs.analchem.7b03148.

(43) Palenzuela, C. L. M.; Novotny, F.; Krupic, P.; Sofer, Z.; Pumera, M. Anal. Chem. 2018, 90, 5753-5757.

(44) Richter, E. M.; Rocha, D. P.; Cardoso, R. M.; Keefe, E. M.; Foster, C. W.; Munoz, R. A. A.; Banks, C. E. Anal. Chem. 2019, 91, 12844-12851.

(45) Squissato, L.; Silva, S. M.; Richter, E. M.; Rocha, D. P.; Munoz, R. A. A. Electrochim. Acta 2020, 335, 135688.

(46) Browne, M. P.; Novotný, F.; Sofer, Z.; Pumera, M. ACS Appl. Mater. Interfaces 2018, 10, 40294-40301.

(47) Kalinke, C.; Neumsteir, N. V; Aparecido, G. de O.; Ferraz, T. V. de B.; dos Santos, P. L.; Janegitz, B. C.; Bonacin, J. A. Analyst 2020, 145, 1207-1218.

(48) McCreery, R. L. Chem. Rev. 2008, 108 (7), 2646-2687.

(49) Hamzah, H. H.; Keattch, O.; Yeoman, M. S.; Covill, D.; Patel, B. A. Anal. Chem. 2019, 91, 12014-12020.

(50) Carmody, W. R. J. Chem. Educ. 1961, 38 (11), 559.

(51) Bin Hamzah, H. H.; Keattch, O.; Covill, D.; Patel, B. A. Sci. Rep. 2018, 8 (1), 9135.

(52) Wirth, D. M.; Sheaff, M. J.; Waldman, J. V.; Symcox, M. P.; Whitehead, H. D.; Sharp, J. D.; Doerfler, J. R.; Lamar, A. A.; Leblanc, G. Anal. Chem. 2019, 91, 5553-5557.

(53) Ayres, Z. J.; Cobb, S. J.; Newton, M. E.; Macpherson, J. V. Electrochem. commun. 2016, 72, 59-63.

(54) Patel, A. N.; Collignon, M. G.; O’Connell, M. a; Hung, W. O. Y.; McKelvey, K.; Macpherson, J. V; Unwin, P. R. J. Am. Chem. Soc. 2012, 134 (49), 20117-20130.

(55) Sarapuu, A.; Helstein, K.; Vaik, K.; Schiffrin, D. J.; Tammeveski, K. Electrochim. Acta 2010, 55 (22), 6376-6382.

(56) Duvall, S. H.; McCreery, R. L. J. Am. Chem. Soc. 2000, 122 (28), 6759-6764.

(57) Li, D.; Batchelor-Mcauley, C.; Chen, L.; Compton, R. G. J. Phys. Chem. Lett. 2020, 11 (4), 1497-1501.

(58) Gomathi, H.; Prabhakara Rao, G. J. Appl. Electrochem. 1990, 20 (3), 454-456.

(59) Batchelor-Mcauley, C.; Kozub, B. R.; Menshykau, D.; Compton, R. G. J. Phys. Chem. C 2011, 115 (3), 714-718.

(60) Rounds, S. A.; Wilde, F. D.; Ritz, G. F. In U.S. Geological Survey; 2013; p http://water.usgs.gov/owq/FieldManual/Chapter6/6.2. 


\section{TOC}

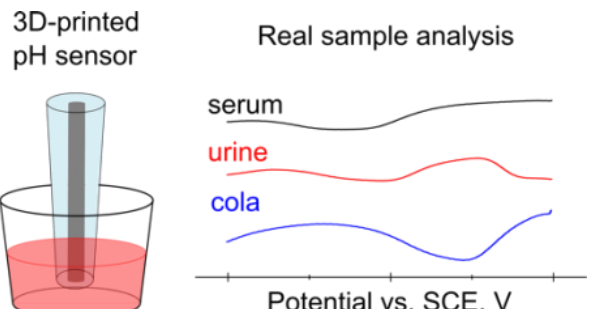

Potential vs. SCE, V 